\title{
A crise de Trabalho e o serviço de "Desurbanização" da Capital. (1914-1924)
}

Dora Shellard Corrêa

Pós-Graduanda do Departamento de História - FFLCH/USP

Este estudo trata da crise de trabalho de 1914 na Capital do Estado de São Paulo e da institutição do serviço de "desurbanização" pela Secretaria de Agricultura, Comércio e Obras Públicas, visando justamente a amenizar o problema da falta de empregos em São Paulo, através da retirada dos sem trabalho para o interior.

A bibliografia sobre o assunto, especialmente com referência ao serviço de "desurbanização", é mínima, não passando de rápidas notas. (1) Nos jornais da época, aqui e ali aparecem comentários sobre a crise e as medidas tomadas para enfrentá-la, demonstrando por parte dos poderes públicos e empresários nacionais uma certa preocupação com o problema. Contudo, estamos no início da $1^{\text {a }}$ Guerra Mundial, e é esta que ocupa as manchetes dos principais diários da cidade.

Por outro lado, o Boletim do Departamento Estadual do Trabalho publica, durante o ano de 1914 e 1915 principalmente, até por volta do início da década de 1920, pelo menos um artigo por ano sobre a crise e - "urbanismo" da Capital, assim como as estatísticas do serviço de "desurbanização". O que nos chamou a atenção é que esse periódico traduz uma grande apreensão da Secretaria da Agricultura, com o fato de haver, segundo seu conceito, um número muito grande de pessoas sem trabalho na cidade, atitude esta que contrasta com o desinteresse dos pesquisadores

(1) - por exemplo:

CARONE, E. A República Velha, Instituições e Classes Sociais. São Paulo: Difusão Européia do Livro, $2^{\text {a }}$ edição revista e aumentada, 1972. pág. 226.

FENELON, D. R. Fontes para o estudo da industrialização no Brasil 1989-1945. in: Revista Brasileira de História. ANPUH, São Paulo, 2 (3), março de 1982. pág. 110 . 
para com o assunto, embora alguns já tenham apontado a gravidade da crise. (2)

O objetivo deste pequeno estudo é, através da leitura desses Boletins do Departamento Estadual do Trabalho, tentar reconstruir o que foi essa crise e o que significou o serviço de "desurbanização" da Capital. Este último, embora tenha sido instituído como uma medida para amenizar a questão do excesso de desempregados na cidade, vem atender também à crise de braços da lavoura, correspondendo a interesses outros e nãr unicamente das camadas urbanas.

\section{1 - A CRISE DO TRABALHO}

Em fins de 1911, o Boletim do Departamento Estadual do Trabalho nos dá a entender que o principal ramo industrial do Estado de São Paulo, a indústria têxtil, estava em expansão:

"Tivemos ocasião de apreciar, em quase todas as fábricas visitadas, os planos de ampliação e de aperfeiçoamento por que já estão passando algumas, e ainda hão de passar as outras em muito pequeno espaço de tempo.

Não será exagerado calcular em mais de 6000 o número de operários exigidos pelas ampliações das referidas fábricas, somente nos municípios de São Paulo, São Bernardo e Santos. No interior do Estado, onde por toda a parte surgem fábricas de tecidos, as necessidades serão ainda maiores". (3)

No entanto, de acordo com o mesmo Boletim, no segundo semestre de 1913, a crise de trabalho já começa a se fazer sentir. Os salários manifestam uma ligeira tendência para a baixa, ..." pricipalmente na dos salários dos operários ocupados nas construções: haviam terminado grande número de obras, outras haviam sido suspensas e poucas eram as que se iniciavam" (4). E no final do ano: "muitas foram as fábricas que reduziram de 20,30 e até $50 \%$ o seu pessoal. Algumas de não pequena importncia, fecharam-se definitivamente ou temporariamente". (5) O número de pessoas sem trabalho aumentou rapidamente. 1914 foi o ano em que a crise de trabalho se apresentou com maior intensidade, "uma verdadeira crise, a mais aguda, talvez de que há memória em São Paulo", (6) "ficou p. 66 .

(2) — Simão, Azis. Sindicato e Estado, São Paulo: Dominus editora, 1966.

(3) - Boletim do Departamento Estadual do Trabalho (DET) ano $1 \mathrm{n}^{\circ} 1 \mathrm{e}$ 2, 4 o trimestre de 1911 e 1 o trimestre de 1912.

(4) - Boletim do DET, 1913, pág. 343.

(5) - Relatório da Agricultura para 1913, p. 5.

(6) - Boletim DET, 1913, p. 5. 
a cidade inundada de desocupados" (7) "nada menos de dez mil pessoas, segundo os cálculos a que procedeu a Seção de Informações deste Departamento, só levando em conta os operários despedidos das inúmeras fábricas". (8)

A crise de trabalho, segundo o Boletim de 1914, ocorreu não só em razão da guerra, mas também como efeito desta que por outro lado levará, do mesmo modo, ao encarecimento dos gêneros de primeira necessidade dificultando ainda mais a sobrevivência dos sem trabalho. Conforme esse periódico, "mal se conheceram aqui as primeiras notícias da guerra, já imediatamente se produziram as suas conseqüências econômicas, como se efetuassemos as nossas compras no estrangeiro para consumir os produtos no mesmo dia da aauisição", (9) Também os preços dos produtos nacionais subiam. Pelos dados colhidos pela Seção de Informações do Departamento Estadual de Trabalho relativamente à situação do mercado atacadista no decorrer do ano de 1914, entretanto, chega-se a que os preços do varejo subiram especulativamente, pois os gêneros de primeira necessidade de produção local foram vendidos a preços inferiores aos existentes durante o ano de 1913 (vide tabela que segue):

Preço do Atacado em 1913 e 1914

1914

1913

açúcar cristal

$18 \$ 500$ a $26 \$ 000$ contra $20 \$ 000$ a $30 \$ 000$

açúcar redondo

$16 \$ 500$ a $22 \$ 000$ contra $17 \$ 000$ a $25 \$ 000$

farinha de mandioca

$8 \$ 000$ a $10 \$ 000$ contra $9 \$ 000$ a $14 \$ 000$

manteiga fresca

$1 \$ 700$ a $2 \$ 600$ contra $2 \$ 000$ a $3 \$ 000$

Fonte: Boletim DET 1914, p. 480

Constatam também, com a instituição das feiras francas em diversos pontos da Capital, que até os gêneros importados poderiam ser vendidos a preços inferiores aos cobrados no comércio varegista. (10)

Conforme a Diretoria Estadual do Trabalho, os elementos que atrapalhavam a solução de imediato da crise do trabalho eram: a deficiência da legislação social vigente e o "urbanismo". (11) Considerava a legislação falha pois não garantia o salário industrial contra as flutuações. Apontava que a maneira pela qual se poderia chegar a algo mais eficiente seria através das convenções coletivas de trabalho, afirmando que estas já eram consagradas na legislação de quase todos os países industriais e nas quais eram incluídas cláusulas que fixavam um prazo para dispensa dos operários, evitando assim o desemprego em massa. Com tal instrumento (uma legisla. ção social mais eficiente, poder-se-ia evitar as despedidas em grandes nú-

(7) - Boletim DET, 1914, p. 468.

(8) - idem, p. 474 .

(9) - idem, p. 478.

(10) - Boletim DET, 1914, p. 478.

(11) - Boletim do DET, ano III № 12 e 13, 3ํ e $4^{\circ}$ trimestre de 1914. 
meros. Também seria uma "garantia contra o desenvolvimento fictício das indústrias, pois com o aumento de seus encargos, estas seriam obrigadas a reduzir as suas atividades a um andamento razoável, semelhando uma prosperidade real e assim se suprimiram as que não tinham capacidade de resistência”.

"Urbanismo"* significava a aglomeração humana em um centro urbano decorrente do afluxo de pessoas para ele. O "urbanismo" na cidade de São Paulo, na segunda década do século XX era decorrente, segundo artigo publicado no Boletim do DET, de três fatores - das indústrias, do estabelecimento dos imigrantes, e da fixação do homem ao campo: "O problema do urbanismo não nos apresenta unicamente em conexão como das indústrias e o da introdução de imigrạntes; relaciona-se também com o da sua fixação, isto é, com a verdadeira colonização interior do Estado" (13).

Esse artigo de 1914 criticava a fascinação exercida pela indústria: "O Brasil tem sido vítima, não só da fascinação exercida pela monocultura, mas também da preferência dada às indústrias nas quais podemos manifestadamente resistir à concorrência”. (14) Segundo ele, a indústria era um desvio de energia, que poderia ser melhor aplicado na exploração de grandes riquezas nacionais, e além disso, ela transformava em "decepções e desastres as esperanças ali fundadas pelos patrões e operários”. (15)

A segunda causa do "urbanismo" era a imigração. A Diretoria de Trabalho indicava que esse fenômeno ("urbanismo") não estava diretamente ligado ao número de imigrantes entrados no Estado, e sim a sua fixação na Capital. A própria Diretoria demonstrou que o pior ano da crise, 1914, foi justamente o momento em que se observou uma diminuição da corrente imigratória européia, em razão da situação política instável em que o mundo se encontrava às vésperas da Primeira Guerra Mundial. O número de imigrantes entrados teria uma queda de mais de $50 \%$ em relação ao ano anterior (vide quadro abaixo).

$\begin{array}{lc} & \text { Imigrantes entrados em São Paulo } 1911-1914 \\ \text { ANO } & \text { TOTAL } \\ 1911 & 64.990 \\ 1912 & 101.947 \\ 1913 & 119.757 \\ 1914 & 48.413\end{array}$

Fonte: Boletim DET, 1914. pág. 467.

(12) - Boletim do DET, 1914, p. 471.

(*) - Termo utilizado pelos diversos Boletins do DET.

(13) - Boletim DET, 1914, p. 475.

(14) - idem.

(15) - idem. 
Conforme o Boletim do Departamento Estadual do Trabalho, contu. do, muitos dos imigrantes que chegavam a São Paulo acabavam se instalando na Capital ao invés de se dirigirem ao campo, como era o objetivo da imigração. Muitos deles eram vistos pela Diretoria como pessoas inadaptáveis e incapazes: "muitos desses homens ficam vivendo na Capital uma vida de parasitas, de mendigos, de inválidos, alimentando-se de esmola, de biscate, quando não de furto". (16) Como forma de evitar a fi. xação desses imigrantes na cidade, é proposto que fosse efetuada a seleção dos imigrantes já no ponto de aliciamento dos mesmos.

A terceira causa do "urbanismo" era a não existência de condições para a fixação do homem ao campo: "O trabalhador emigra do interior para a Capital, não só porque atende a uma solicitação, mas também porque recebe uma pressão; não só porque a cidade o atrai, mas também porque o campo não o retém”.(17) Como medida para fixar o homem, "era proposta a colonização do interior, da zona considerada abandonada ,com o estabelecimento da pequena propriedade".(18) Caberia, entretanto, acentuar que essa proposta não era pensada em termos de crítica ao fornecimento de braços à lavoura cafeeira, como alguns poderiam pensar, muito pelo contrário, o trabalho dos imigrantes na zona cafeeira era apontada

como o meio para que se acumulasse o pecúlio necessário para a aquisição de um lote de terra. Propunha até a imigração temporária da população rural brasileira, "sem pecúlio, sem hábitos de trabalho contínuo, sem meios de defesa contra as menos graves eventualidades",(19) dispersa na "vasta região, em máxima parte abandonada",(20) para onde houvesse emprego, até que tivessem acumulado um pecuilio, quando então "regressariam, já capazes de exercer rendosamente os místeres agrícolas”.(21) Portanto o trabalho nas fazendas era visto como meio para que o colono se tornasse proprietário de um sítio agrícola. Caberia ao Estado "promover o desenvolvimento da pequena lavoura e a prosperidade dos trabalhadores rurais”.(22)

O "urbanismo" não era um problema apenas da capital do Estado, outras cidades alertavam-se também com fenômeno semelhante. Mas ainda que o Departamento Estadual do Trabalho afirmasse em 1916 que as medidas tomadas para a "desurbanização", limitadas até então a São

(16) - Boletim DET, 1914, p. 471.

(17) - Boletim DET, 1914, p. 475.

(18) - idem, p. 476.

(19) - idem.

(20) - idem, p. 476.

(21) - idem, p. 477.

(22) - Boletim DET, 1914, p. 476. 
Paulo, seriam estendidas para outros centros urbanos como por exemplo Sorocaba (23), não há nada que indique que isso se efetivou.

Não era visto também como um fenômeno tipicamente brasileiro. Ele era comum a diversos países industriais, sendo as causas geralmente as mesmas: a atraçâo psicológica exrcida pela cidade e o êxodo rural. Os diversos números do Boletim do DET publicam artigos abordando o "urbanismo" em locais como a França por exemplo: "A crise do trabalho tão universalmente sentida quanto as outras consequiências da situação eulropéia".

Frente à crise de trabalho e ao fenômeno do "urbanismo", conforme - Boletim do DET aponta, foram tomadas, em 1914, medidas pelo Estado "capazes de concorrer para a desurbanização dos sem trabalhos", (25) são elas:

- o Secretário de Agricultura, Comércio e Obras Públicas propôs aos prefeitos do interior que formassem comitês em seus municípios, com a incumbência de promover a colocação de operários sem trabalho;

- foi organizada uma Comissão de Socorros pelo Secretário da Justiça e de Segurança Pública, que convocou os jornalistas para discutirem a situação. Essa Comissão, após constituída, passou a engariar recursos a fim de acudir aos necessitados, mediante Comissões Distritais formadas em todos os bairros da Capital;

- a Diretoria de Colocação passou a fornecer informações recebidas dos prefeitos, sobre emprego no interior, a fim de colocar os sem trabalho;

- e finalmente, a Diretoria de Colocação facilitava o encaminhamento dos desempregados e de suas famílias para o interior através da concessão de passagens grátis. Esse é, de acordo com a Diretoria, o serviço de "desurbanização" da Capital e que trataremos mais detalhadamente a seguir. (26)

\section{2 - O SERVIÇO DE "DESURBANIZAÇÃO"}

O fornecimento de passagens de trem grátis para o interior aos sem trabalho (27) da Capital de todas as profissões, já previsto em lei desde

(23) - Boletim DET, ano V, no 21, 40 trimestre de 1916.

(24) - Boletim DET, 1915, p. 5.

(25) - Boletim DET, 1914, p. 473.

(26) - Boletim DET, ano IV, no 14, 10 trimestre de 1915.

(27) - O Boletim do DET dividia os sem trabalho em dois grupos: os desocupados permanentes, que se confundem nos períodos de crise com os operários desempregados; e os desocupados temporários, trabalhadores que se encontram momentaneamente desocupados em razão da crise. Apesar dessa diferenciação, es- 
1906. (28) O decreto $\mathrm{n}^{\circ} 2400$ de 9 de julho de 1913, em seu' artigo 389, faz semelhante disposição, impondo o mesmo requisito, ou seja, de que o trabalhador deveria ser contratado previamente ou perante a Agência Oficial de Colocação, ou ainda, apresentar carta de patrão. A passagem só seria fornecida uma única vez para si e família com direito ao transporte de suas bagagens.

Aparentemente será apenas a partir de agosto de 1914 que essa disposição será propagandeada e posta em prática pela Agência Oficial de Colocação, com uma pequena alteração contudo, que dava o direito temporariamente também aos sem trabalho que não houvessem encontrado um patrão de serem beneficiados do transporte gratuíto. Essa medida, tomada por um espaço de tempo que não conseguimos determinar ao certo, veio, como já foi visto, em resposta à crise do trabalho da Capital.

Para propagandear essa providência, foram afixados cartazes nas Estradas de Ferro cientificando tais pessoas das facilidades oferecidas pelo Estado para colocar-se no interior; da mesma forma, houveram publicações semelhantes nos locais de distribuição de socorros e nos principais periódicos da Capital. (29) Pedia-se também "aqueles cavalheiros que empregassem os seus bons ofícios junto às pessoas socorridas pela Comissão" (Comissões distritais de socorros públicos) "de que faziam parte, no sentido de lhes mostrar a conveniência de se aproveitarem dessas facilidades”. (30)

Em 1924 ainda eram fornecidas passagens grátis aos sem trabalho da Capital. Estava em vigor contudo, a restrição disposta no artigo 389 do decreto $\mathrm{n}^{\circ} 2.400$, ou seja, a exigência de apresentação de contrato de

se períodico não nos informa se esses dois grupos foram tratados de forma diversa pelo poder público. (vide os Boletins do DET para o ano de 1914 e 1915).

(28) - Lei $1045 \mathrm{C}$ de 27 de dezembro de 1906, artigo 68.

(29) - $O$ Estado de São Paulo, 12 de agosto de 1914, pág. 6, publica o seguinte edital da Agência Oficial de Colocação do Departamento Estadual do Trabalho: "De ordem do Exmo. Sr. Dr. Secretário de Estado dos Negócios aos trabalhadores agrícolas e de todas as profissões manuais, residentes nesta cidade e que se acharem atualmente sem serviço, que a Agência Oficial de Colocação, deste Departamento, está autorizada a facilitar contratos de trabalhos aos que desejarem colocar se fora da Capital tanto os que se contratarem como os que não arranjarem patrão antes da partida terão passgem gratuita, com direito ao transporte de bagagens, para qualquer ponto do interior do Estado.

A passagem será fornecida uma única vez perdendo o direito auxílio os que se não apresentarem ao embarque marcado pela Agência, que, para esse serviço, funcionará nos dias úteis, das 8 às 16 horas.

Departamento Estadual do Trabalho, São Paulo, 5 de agosto de 1914. Luiz Ferraz - Diretor"

(30) - Boletim DET, 1914, p. 473. 
trabalho ou equivalente. (31) A concretização desse artigo assim como a medida tomada em 1914 foram denominadas muitas vezes pela Agência Oficial de Colocação de serviço ou movimento de desurbanização" da Capital.

Os Boletins do DET relacionam uma estatística das pessoas saídas de São Paulo por esse serviço de 1913, embora esse mesmo periódico nos dê indicações de que essa migração subsidiada só foi instituída realmente em 1914, até 1923. O total de trabalhadores encaminhados para o interior nesse período foi de 7.860 pessoas, $23,83 \%(17,847)$ apenas no ano de 1914 (vide tabela que segue).

Total de pessoās saídas da Capital pelo serviço de desurbanização. $1913-1923$

ANO

1913

1914

1915

1916

1917

1918

1919

1920

1921

1922

1923
TOTAL DE PESSOAS SAIDAS

6.667

17.847

8.653

5.982

5.744

4. 176

4.044

6.177

6.151

3.715

5.712

Fonte: Boletim DET 1917, ano VI No 23, 2 \% trimestre

Boletim DET 1924, ano XXIV, No 53, 4ㅇ trimestre

Os objetivos da Secretaria com a instituição do serviço de "desurbanização" eram: num primeiro instante, "desurbanizar" a Capital, e num segundo, fornecer braços à grande lavoura. Este último, passará com o tempo a ser colocado como a principal meta do serviço. Embora os ca-

(31) - O Boletim DET, 1924, p. 481 publica o seguinte aviso:

"Aviso aos trabalhadores

A Agência Oficial de Colocação, do Deptọ Estadual do Trabalho, continua a facilitar contratos aos trabalhadores agrícolas e de todas as profissões manuais, que se acharem sem trabalho e desejarem colocar-se fora da Capital.

Tanto os que se contratarem perante a Agência como os que apresentarem carta de patrão, terão passagem gratuita, para si e família, com direito ao transporte de bagagens, para qualquer ponto do interior do Estado.

A passagem será fornecida uma única vez, perdendo o direito a esse auxílio os que se não apresentarem ao embarque marcado pela Agência, que funciona, para esse serviço, nos dias úteis, das oito às dez horas da manhã". 
feicultores continuassem, nos anos após guerra, a reclamar da falta de braços, terão a seu favor também esse mecanismo que dirigia e subsidiava a migração interna para o campo.

Cnaccarini (32) faz referência à violência com que ocorria a migração forçada da cidade para o campo em 1913, através da ação conjunta da Secretaria de Segurança e Agência Oficial de Colocação. Os Boletins não se referem ao que acontecia antes da instituição do movimento de "desurbanização”, entretanto, em 1917 é publicado um artigo de João Papaterra Limongi onde este toca na ação da polícia dirigindo, conforme denomina, os vadios para o serviço:

"As estatísticas acusam cifras humilhantes de desocupados, vadios, de oscilantes, gente sem profissão, sem iniciativa, sem meios de vida, sem recursos. Por algum tempo, a ação policial caminhou violentamente essas criaturas para o trabalho.

Hoje ação suasória de repartições como o Serviço de Povoamento do Ministério da Agricultura e o Departamento do Trabalho de São Paulo facilita a colocação na lavoura aos sem trabalho das duas principais cidades do país". (33)

Vindo substituir a violência ou mesmo utilizando-a, a Seçretaria da Agricultura, através da cessão de passagens grátis aos sem trabalho da Capital, interfiria diretamente no movimento migratório interno.

\section{CONCLUSÃO}

Conforme os diversos números de Boletim do DET apontam, o "urbanismo" era um fenômeno constante na Capital, pelo menos a partir da segunda década do século XX. A crise de trabalho de 1914 representava o momento em que esse fenômeno passa a gerar, em vista da sua dimensão, um desconforto na cidade de São Paulo: "Já começava a causar nesta $\mathrm{Ca}$ pital um pronunciado mal-estar” (34). Embora o Departamento E . do Trabalho defendesse uma legislação social que desse maior proteção aos trabalhadores nesses momentos de crise, propondo ao mesmo tempo a criação de mais empregos através da revitalização de algumas obras públicas, uma das medidas concretas tomadas por esse órgão a qual se prolongaria pelo menos por mais dez anos, seria a retirada física de parte dos desocupados da cidade.

A preocupação do Departamento do Trabalho, em 1914, parecia ser não com o destino dos desocupados, com o seu emprego, e sim com o au-

(32) - CNACCARINI, José César. Latifúndio e proletariado. São Paulo, editora Polis LTDA, 1980. p. 21.

(33) - Boletim DET, 1917, p. 458.

(34) - Boletim do DET, 1914, p. 472. 
mento do número de pessoas sem trabalho na Capital, o que "acarretava um mal-estar de gravidade muitas vezes agudíssima". (35) A atenção central do Governo estava voltada para as medidas e ações que levassem à dimintição rápida do número de desocupados da cidade de São Paulo, com a retirada dos "que só contavam com esse recurso para a sua manutenção" (36): o salário que lhes havia sido suprimido em razão do desemprego.

O serviço de "desurbanização", além de aliviar a tensão social existentes na Capital em vista do acúmulo de pessoas sem trabalho, veio também impulsionar artificialmente, a rotação da mão-de-obra entre os setores urbano e rural da economia. Segundo o próprio Departamento Estadual do Trabalho aponta, o fluxo de pessoas do campo para a cidade era espontâneo; uma parte do movimento de trabalhadores da cidade para o campo era, entretanto, subsidiada. Tal interferência direta do Estado no movimento interno já era previsto desde 1906, pela Lei 1045C de 27 de dezembro.

A "desurbanização" da Capital, embora pudesse ser vista, por um lado, como desfavorável à burguesia urbana por interferir no mercado de trabalho diminuindo a oferta de mão de obra, por outro, protegia as suas propriedades e a eles mesmos das consequiências advindas de um número considerado mutito grande de desocupados estacionados na cidade. Além disso, não extinguia totalmente o número de pessoas sem trabalho da Capital: "Como é bem de ver, não se suprimiu totalmente a desocupação". (37) E, ademais, embora a imigração européia tenha diminuído durante a guerra, ano a ano chegavam levas de imigrantes vindos da Europa, parte dos quais jamais seguia para o campo, número este de trabalhadores que at1mentava com o fluxo contínuo de pessoas que migravam do campo.

O serviço de "desurbanização" era interessante para os fazendeiros, especialmente para os cafeicultores, uma vez que os desocupados da Capital eram jogados no interior via estrada de ferro, sem haver, pelo lado dos fazendeiros nehum comprometimento: as passagens eram pagas pelo Governo, e não havia necessidade, em determinado momento, de existir um contrato de trabalho firmado anteriormente. Dessa forma, a cafeicultura passou a ter à sua disposição uma parte da mão de obra imigrante e migrante que para ela deixara de ir ou que para ela se retirara. Contudo, apesar do movimento de "desurbanização" garantir o aumento da oferta de mão de obra, os fazendeiros continuariam a reclamar por mais braços: " $E$ verdade que diminuiu bastante o número de desocupados que enxameavam nesta cidade; a lavoura porém ainda pede braços". (38)

(35) - Boletim do DET, 1914, p. 471.

(36) - Idem.

(37) - Boletim DET, 1914, p. 474.

(38) - Boletim DET, 1915, p. 606. 
O serviço de "desurbanização" não só não foi instaurado para resolver o problema do sem trabalho, como também era desfavorável a eles. Os trabalhadores deslocados em 1914 por esse serviço saíam de um centro em que, mesmo desempregados, poderiam manter-se através de biscates e esmolas como o próprio Boletim do DET mostra. (39) Eram jogados no interior sem emprego garantido e sem a opção de retornarem à Capital, mesmo continuando desempregados.

Enfim o que podemos concluir com a leitura dos Boletins do DET, é que o serviço ou movimento de "desurbanização" vinha atender tanto à burguesia urbana como aos grandes produtores. Está visível nos textos analisados, na Lei $1045 \mathrm{C}$ de 1906 e no decreto 2400 de 1913 já referidos anteriormente, que essa medida facilitava uma circulação da mão de obra entre os setores rural e urbano da economia. bem como, era mais uma arma para garantir um fluxo contíntıo de braços para a lavoura cafeeira.

\section{BIBLIOGRAFIA}

CARONE, Edgard. A República Velha, Instituiçôes e Classes Sociais. São Paulo: Difusão Européia do Livro, 2ạ edição revista e aumentada, 1972.

CNACCARINI, José César. Latifúndio e proletariado. São Paulo, editora Polis Ltda, 1980 .

DEAN, Warren. A Industrializaçăo de Săo Paulo. São Paulo: Difel, 1971.

FAUSTO, Boris. Trabalho Urbano e Conflito Social (1890-1920). Rio de Janeiro; Difel, 1977.

FENELON, Déa Ribeiro, Fontes para o estudo da industrialização no Brasil. 1889-1945. in: - Revista Brasileira de História, ANPUH São Paulo, 2(3), março de 1982.

LOVE, Joseph. A Locomotiva, Rio de Janeiro: Editora Paz e Terra, 1982.

LUZ, Nícia Vilela. A Luta pela Industrialização do Brasil. São Paulo: Editora Alfa-Omega, 1975 .

MORSE, Richard M. Formação Histórica de Säo Paulo. São Paulo: Difusão Européia do Livro, 1970.

RODRIGUES, Leôncio Martins. Conflito Industrial e Sindicalismo no Brasil. São Paulo: Difusão Européia do Livro, 1966.

SIMÃO, Azis. Sindicato e Estado. São Paulo: Dominus editora, 1966.

SINGER, Paul. Desenvolvimento Econômico e Evolução Urbana. São Paulo: ed. Nacional, 1a reimpressão, 1974.

(39) - Boletim DET, ano III, no 12 e 13, 39 e 49 trimestre de 1914.

Departamento de História - FFLCH/USP 